\title{
Low-Cost and High-Gain SIW Circularly Polarized Circular-Horn-Loaded Antenna for Broadband Millimeter-Wave Applications
}

\author{
Ming $D U^{1}$, Jun $X U^{1}$, Yuliang $D O N G^{2}$, Xiao DING ${ }^{1}$ \\ ${ }^{1}$ School of Physical Electronics, University of Electronic Science and Technology of China, Chengdu, China \\ ${ }^{2}$ National Institute of Measurement and Testing Technology of China, Chengdu, China \\ mingdu_uestc@163.com,xujun@uestc.edu.cn,dongyull@163.com,xding@uestc.edu.cn
}

Submitted January 1, 2017 / Accepted April 14, 2017

\begin{abstract}
A$ wideband, low-cost and high-gain circularly polarized (CP) circular-horn-loaded antenna based on substrate integrated waveguide (SIW) technology operating at Ka band is presented. The proposed antenna, which is built on a single-layer substrate, consists of five parts: a short-ended SIW, a center-symmetric wide slot, an L-shaped probe, a circular horn and a transition from SIW to air-filled rectangular waveguide for measurement. The slot is etched on the upper ground of the SIW, while the L-shaped probe for generating $C P$ wave is printed inside the slot and connected to the SIW. A circular horn is also loaded on the surface of the SIW slot for high gain. Then, the proposed antenna with a dimension of $45 \times 45 \times 24.16 \mathrm{~mm}^{3}$ was fabricated and measured. The measured results show that the antenna has a wide impedance bandwidth of $28.6 \%$ from 30 to $40 \mathrm{GHz}$ for $\left|S_{11}\right| \leq 10 \mathrm{~dB}$ and a wide axial ratio (AR) bandwidth of $22.2 \%$ from 32 to $40 \mathrm{GHz}$ for $A R \leq 3 \mathrm{~dB}$. The measured maximum gain is $15.6 \mathrm{dBi}$ at $36 \mathrm{GHz}$ with slight fluctuations over the 30-40-GHz frequency range.
\end{abstract}

\section{Keywords}

Substrate integrated waveguide (SIW), circularly polarized $(\mathrm{CP})$, horn, low cost, high gain, broadband millimeter-wave $(\mathrm{mmW})$ antenna

\section{Introduction}

For the merit of low loss [1], the substrate integrated waveguide (SIW) technology has received much attention in millimeter-wave ( $\mathrm{mmW})$ wireless systems [2], such as front-end systems [3], [4], filters [5], antennas [6], [7], etc. As the indispensable components of $\mathrm{mmW}$ wireless systems, antennas play an important role in information transmission. Meanwhile, there has been an increasing interest in the investigation of circularly polarized (CP) antennas because of their advantages of suppressing the multi-path interference and reducing the polarization mismatch [8]. Therefore, over past twenty years, many kinds of $\mathrm{CP}$ antennas based on SIW technology have been investigated [9-13].

The SIW slot covered by a rotated strip or a CP patch may be one common method for generating $\mathrm{CP}$ radiation [9], [10]. For example, a low-temperature co-fired ceramic integrated SIW slot antenna covered by a rotated strip was proposed in [9]. This antenna achieves a 3-dB axial ratio (AR) bandwidth of $11.6 \%$. [10] presents a SIW slot array antenna covered by corner-truncated $\mathrm{CP}$ array patches. The measured -15-dB $\left|\mathrm{S}_{11}\right|$ and 3-dB AR bandwidths of this antenna are about $6.4 \%$ and $2.86 \%$, respectively. This method can achieve good CP performance. However, the multi-layer technology is always needed. The multi-layer technology merits high degree of freedom of designing and beam forming capability, but the cost is high.

The multiple feeding is also a good method for generating CP radiation, and this kind of antenna always shows wide bandwidth. In [11], a differential-fed CP planar aperture antenna based on SIW technology operating at $60 \mathrm{GHz}$ was proposed. There are two feeding ports in one antenna element. The proposed four-element array could achieve wide 3-dB AR bandwidth of $16.7 \%$ (56 to $66.2 \mathrm{GHz}$ ) within its $-10-\mathrm{dB}\left|\mathrm{S}_{11}\right|$ bandwidth and stable gain throughout the operating bandwidth with a maximum of $14.6 \mathrm{dBi}$. The differential feeding is useful in differential $\mathrm{mmW}$ monolithic integrated circuits and can achieve stable and symmetric radiation patterns. Nevertheless, for other applications such as phased arrays, the feeding network is complex.

Single-fed CP SIW antennas are always research focus because of low cost, simple structure and easy fabrication. A CP circular ring-slot antenna embedded in singlelayered SIW operating at $\mathrm{X}$ band was proposed in [12]. The measured results exhibit that the antenna has a broadband impedance bandwidth of $18.74 \%$ for $\operatorname{VSWR} \leq 2$ and a $3-\mathrm{dB}$ AR of $2.3 \%$. In [13], the SIW cavity-backed CP antennas using two different feeding transitions were presented. The measured results prove that broadband impedance bandwidth of $17.32 \%$ and $14.42 \%$ under the criteria of less than VSWR 2:1 and 1.5:1, respectively, were obtained and a $3-\mathrm{dB}$ AR of $2.34 \%$ with a maximum gain of $7.79 \mathrm{dBic}$ was accomplished by using the proposed antenna 


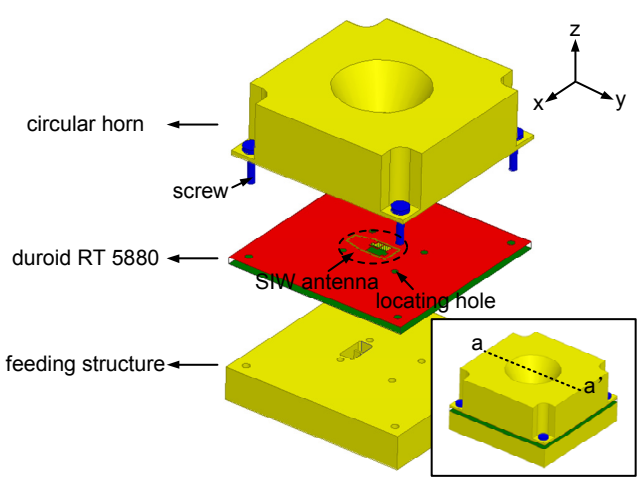

Fig. 1. Proposed antenna configuration.
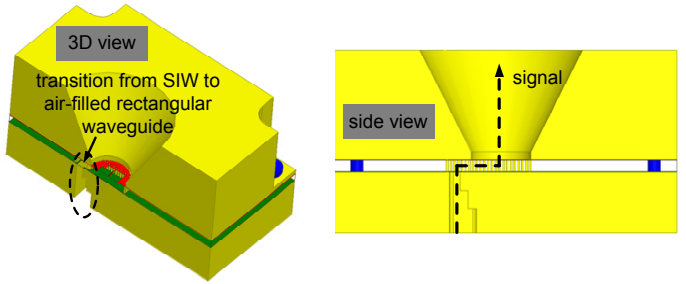

Fig. 2. 3D and side views of the a-a' profile of the proposed antenna.

with coax-to-SIW transition operating at the $\mathrm{X}$ band of $10 \mathrm{GHz}$ center frequency. Both the two antennas are singlefed, low-cost and can achieve good CP radiation pattern, however the 3-dB AR bandwidth is relatively narrow.

Therefore, the design of a low-cost single-fed SIW CP antenna with both wide impedance and AR bandwidths is not an easy task.

In addition, high gain is also necessary for $\mathrm{mmW}$ applications because of the high transmission and propagation losses at $\mathrm{mmW}$. Forming an array may be the most common method to achieve high gain. This method merits easy integration with other planar circuits. However, for parallel-fed arrays, because of the large width of the SIW, the radiating elements and feeding network of this kind of array are not easy to be built on a single substrate at the same time in a simple and tighten way, especially when the dielectric permittivity of the substrate is small, the radiating element needs multiple feeding and a square array with large number of elements is needed. As a result, the design of the feeding network is not so easy, the feeding network is complex which will cause extra loss and limitation of the number of elements of a square array. The series-fed array can solve this problem, but the bandwidth is usually narrow [10].

To address the problems above, this paper presents a low-cost single-fed SIW CP antenna built on single-layer substrate with both wide impedance and AR bandwidths. A circular horn is also loaded on the surface of the proposed SIW CP antenna to forming a CP horn antenna for high gain. This kind of antenna will decrease the chance of a dense integration but it needs no feeding network. Therefore, the structure is simple and the loss caused by the feeding network is low. And compared with the multi-layer technology, the cost of the extra metal horn is low.

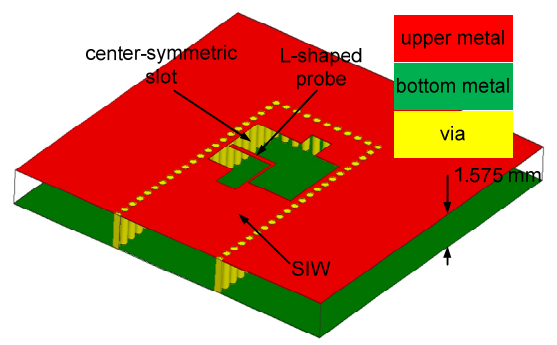

(a)

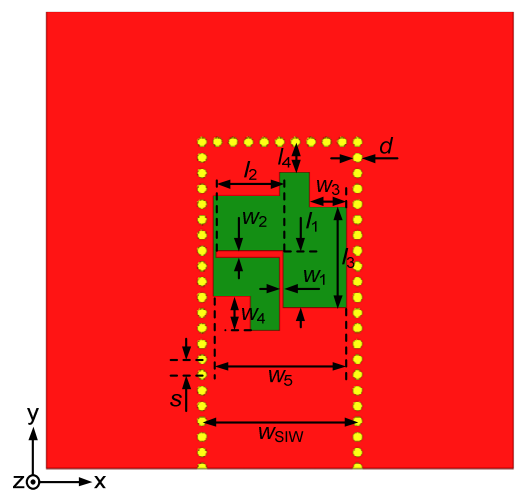

(b)

Fig. 3. (a) $3 \mathrm{D}$ and (b) top views of the proposed SIW antenna.

Owing to the above advantages, the proposed antenna is suitable for low-cost, high-gain and broadband $\mathrm{mmW}$ applications.

\section{Antenna Design}

\subsection{Total Antenna Configuration}

The proposed antenna configuration is shown in Fig. 1. It consists of a duroid RT 5880 substrate, a metal circular horn, and a metal feeding structure for measurement. The substrate used is duroid RT 5880 with dielectric permittivity $\varepsilon_{\mathrm{r}}=2.2$, loss tangent $\tan \delta=0.0009$ and thickness of $1.575 \mathrm{~mm}$. For seeing the proposed antenna more clearly, the $3 \mathrm{D}$ and side views of the a-a' profile of the proposed antenna are also plotted in Fig. 2.

\subsection{SIW Antenna}

As the SIW antenna is the excitation of the circular horn, we start our design from the SIW antenna. Figure 3 shows the 3D and top views of the SIW antenna. As shown, a center-symmetric wide slot is etched on the upper ground of a short-ended SIW. In order to generate CP wave, an L-shaped probe is printed inside the slot and connected to the SIW. The detailed dimensions are: $d=0.3 \mathrm{~mm}$, $s=0.5 \mathrm{~mm}, \quad w_{\text {SIW }}=5 \mathrm{~mm}, w_{1}=0.1 \mathrm{~mm}, \quad w_{2}=0.2 \mathrm{~mm}$, $w_{3}=1.2 \mathrm{~mm}, w_{4}=1.1 \mathrm{~mm}, w_{5}=4.3 \mathrm{~mm}, l_{1}=1.81 \mathrm{~mm}$, $l_{2}=2.14 \mathrm{~mm}, l_{3}=3.25 \mathrm{~mm}$ and $l_{4}=0.975 \mathrm{~mm}$. The evolution of the proposed antenna is depicted in Fig. 4 to explain the CP performance of the SIW antenna. All the three antennas have been discussed here, .i.e., antenna 1 (ant 1), antenna 2 (ant 2), and antenna 3 (ant 3). Ant 1 is the SIW 


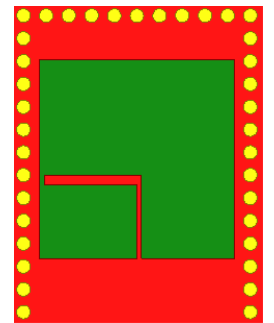

ant 1

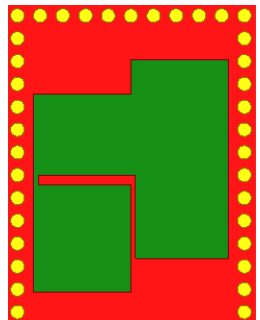

ant 2

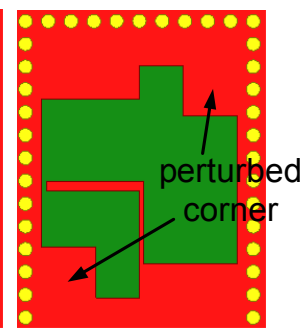

ant 3
Fig. 4. Evolution of the SIW antenna.

antenna with a rectangular slot. Ant 3 is the proposed SIW antenna with a corner-perturbed center-symmetric slot. And ant 2 is the SIW antenna with a basic centersymmetric slot.

The effects of the each step of all three antennas are described in Fig. 5. The commercial electromagnetic software HFSS was used to obtain all the simulated results. It can be seen that ant 1 has the worse $\left|S_{11}\right|$. Ant 3 has a wide impedance bandwidth of $23.8 \%$ from 31.5 to $40 \mathrm{GHz}$ for $\left|\mathrm{S}_{11}\right| \leq-10 \mathrm{~dB}$. The impedance bandwidth of ant 2 is almost the same with that of ant 3 but shifts to lower frequencies. The AR is improved gradually from ants 1 to 3 . The AR bandwidth of ant 1 with the highest center frequency is the narrowest. The 3 -dB AR bandwidth of ant 3 is $21.3 \%$ from 31.5 to $39 \mathrm{GHz}$.

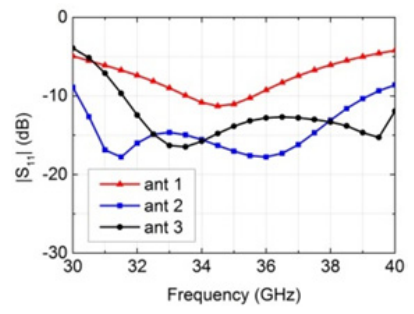

(a)

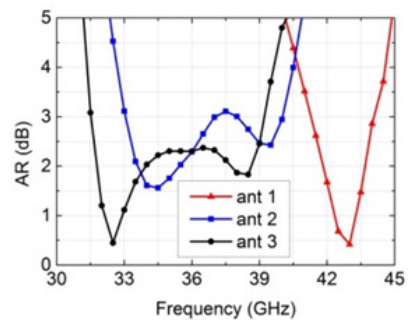

(b)
Fig. 5. Simulated (a) $\left|S_{11}\right| S$ and (b) ARs for antennas 1-3.

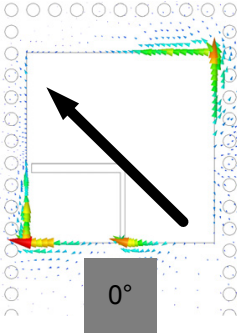

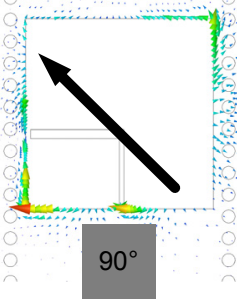

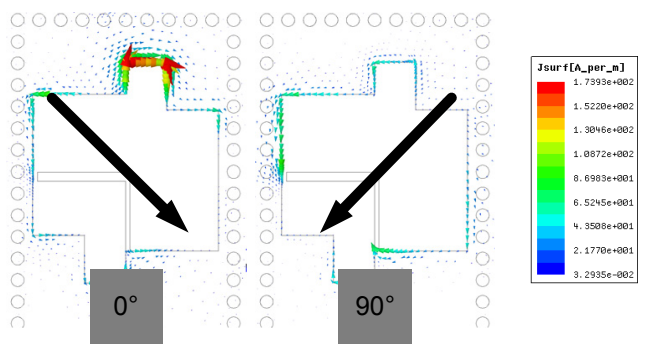

(b)

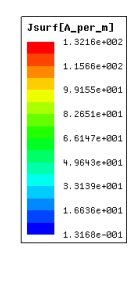

Fig. 6. Simulated currents on the surface of the SIW slot of (a) ant 1 and (b) ant 3 at $35 \mathrm{GHz}$ and different phases.
The shape of the slot is the key for achieving good CP performance. By shaping the slot into central symmetry with perturbed corner, the currents on the SIW slot will be improved because of the rotating edges. For illustrating this point clearly, the simulated currents on the surface of the SIW slot of ants 1 and 3 at $35 \mathrm{GHz}$ and different phases are plotted in Fig. 6. It can be seen that the currents of ant 1 are in the same direction at $0^{\circ}$ and $90^{\circ}$, therefore the SIW slot of ant 1 generates the linearly polarized wave. On the contrary, the currents of ant 3 rotate clockwise from $0^{\circ}$ to $90^{\circ}$ which results in left-handed CP (LHCP) radiation. Righthanded CP (RHCP) radiation can be obtained by adopting a mirror image of the presented configuration. Therefore, the LHCP will be the co-polarization, while the RHCP will be the cross-polarization.

$\mathrm{CP}$ is generated by two orthogonal E vectors with equal amplitude and $90^{\circ}$ phase difference. The two orthogonal $\mathrm{E}$ vectors are generated by the horizontal and vertical parts of the L-shaped probe in the proposed SIW antenna. The rectangular SIW slot is influenced by the probe differently, so the SIW slot cannot generate CP wave. By shaping the slot into central symmetry with perturbed corner, the SIW slot will be influenced almost equally. Therefore, the SIW slot can generate CP wave.

The simulated E-field distributions on the surface of the SIW slot of ant 3 at $35 \mathrm{GHz}$ and different phases are also plotted in Fig. 7. The directions of the E-field rotate clockwise from $0^{\circ}$ to $270^{\circ}$ which also demonstrates that the LHCP will be the co-polarization, while the RHCP will be the cross-polarization.

The simulated radiation patterns of ant 3 at $35 \mathrm{GHz}$ are shown in Fig. 8. It can be seen that good broadside radiation is achieved. The LHCP components in both planes are the co-polarization while the RHCP components

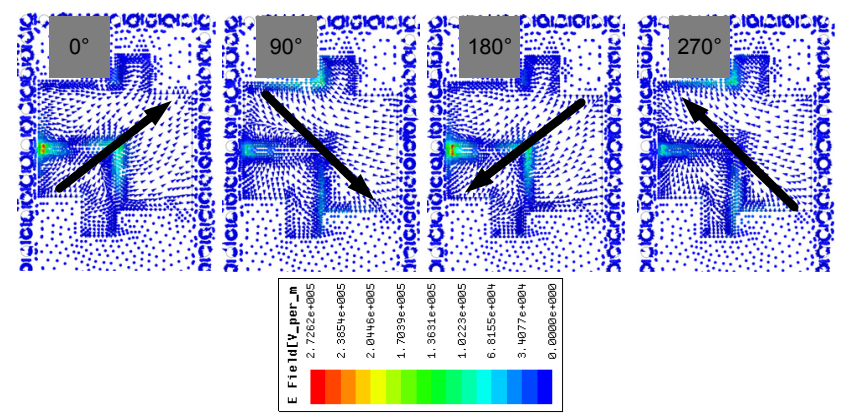

Fig. 7. Simulated E-field distributions on the surface of the SIW slot of ant 3 at $35 \mathrm{GHz}$ and different phases.

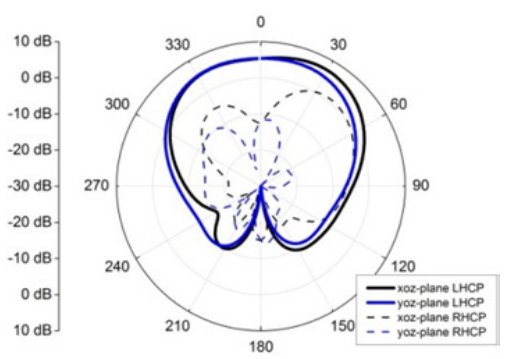

Fig. 8. Simulated radiation patterns of ant 3 at $35 \mathrm{GHz}$. 
in both planes are the cross-polarization. The gain of ant 3 is $5.55 \mathrm{dBi}$. Meanwhile, the proposed SIW antenna merits good front-to-back ratio (FBR) $35.55 \mathrm{~dB}$.

\subsection{Feeding Structure}

The transition from SIW to air-filled rectangular waveguide proposed in [14] is used to feed the SIW antenna. The configuration of the transition with detail dimensions is shown in Fig. 9. The simulated $\left|S_{11}\right|$ and $\left|S_{12}\right|$ of the transition is shown in Fig .10. It can be seen that the simulated return loss and insertion loss of the back-to-back transition are better than 10 and $0.5 \mathrm{~dB}$ from 30 to $40 \mathrm{GHz}$.

\subsection{Circular-Horn-Loaded SIW Antenna}

In order to obtain high gain, a circular horn is loaded on the surface of the SIW antenna to forming a CP horn antenna.

Traditionally, the horn antenna is LP and it can be turned into a $\mathrm{CP}$ antenna by using a circular-wave polarizer [15], [16]. However, this type of CP horn antenna has large size. A dual CP rectangular horn antenna with a chiral metamaterial was presented in [17]. The antenna achieves LHCP performance in the frequency range of $12.4 \mathrm{GHz}$ to $12.5 \mathrm{GHz}$, and RHCP performance in the range of 14.2 $\mathrm{GHz}$ to $14.4 \mathrm{GHz}$. The circular polarization also can

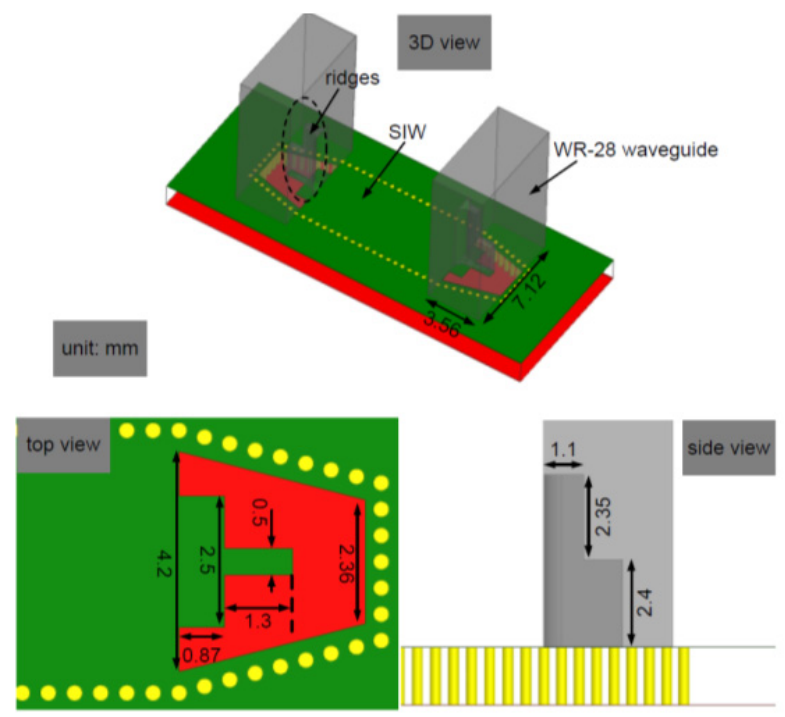

Fig. 9. Configuration of the back-to-back transition from SIW to air-filled rectangular waveguide with detail dimensions.

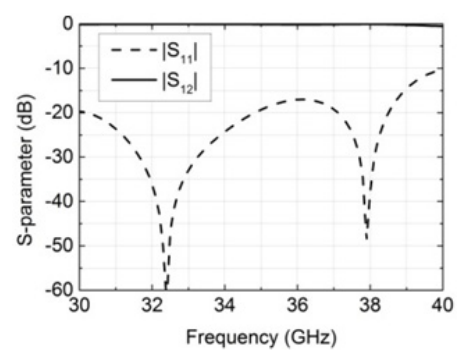

Fig. 10. Simulated $\left|S_{11}\right|$ and $\left|S_{12}\right|$ of the back-to-back transition.

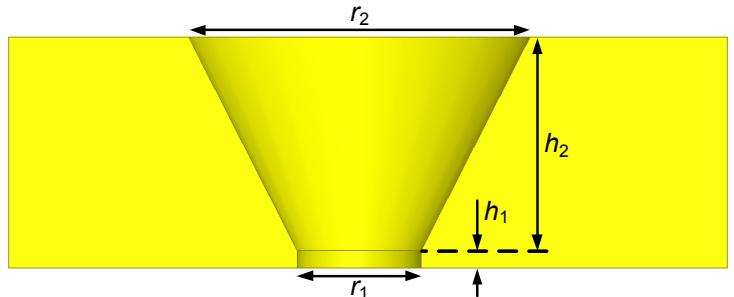

Fig. 11. Configuration of the circular horn.

be obtained by truncating the horn properly [18]. A wideband CP circular horn antenna fed by an L-probe was proposed in [19]. It is a good method to achieve circular polarization owing to the simple structure and low cost.

The CP horn antenna can be obtained using all the above methods, but all of them are fed by a rectangular waveguide or a coaxial cable. Therefore, extra transition is needed to connect the antenna to the planar circuit which will introduce extra loss. The CP horn antenna proposed in this paper is fed by the SIW antenna directly which can solve this problem.

Figure 11 shows the configuration of the circular horn. The detail dimensions are: $r_{1}=0.78 \mathrm{~mm}, r_{2}=21.42 \mathrm{~mm}$, $h_{1}=1.12 \mathrm{~mm}$ and $h_{2}=13.4 \mathrm{~mm}$.

In order to achieve the best performance, some values of the parameters of the SIW antenna are tuned slightly. The tuned parameters are (original value to present value): $w_{2}=0.2$ to $0.1 \mathrm{~mm}, w_{3}=1.2$ to $0.82 \mathrm{~mm}, w_{4}=1.1$ to $0.75 \mathrm{~mm}, l_{1}=1.81$ to $1.75 \mathrm{~mm}, l_{2}=2.14$ to $2.1 \mathrm{~mm}, l_{3}=$ 3.25 to $3.69 \mathrm{~mm}$ and $l_{4}=0.975$ to $1 \mathrm{~mm}$. The values of the other parameters are not changed.

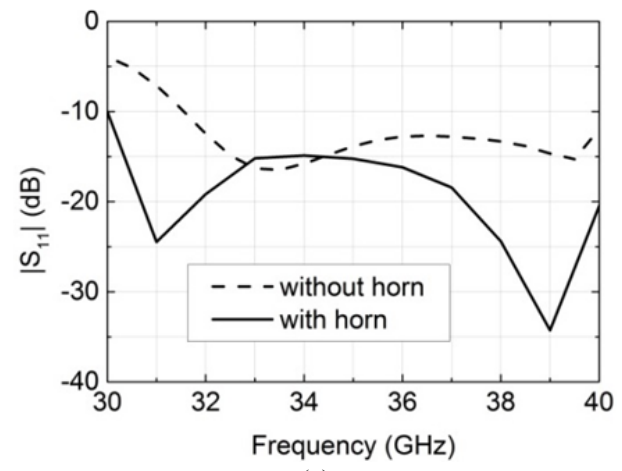

(a)

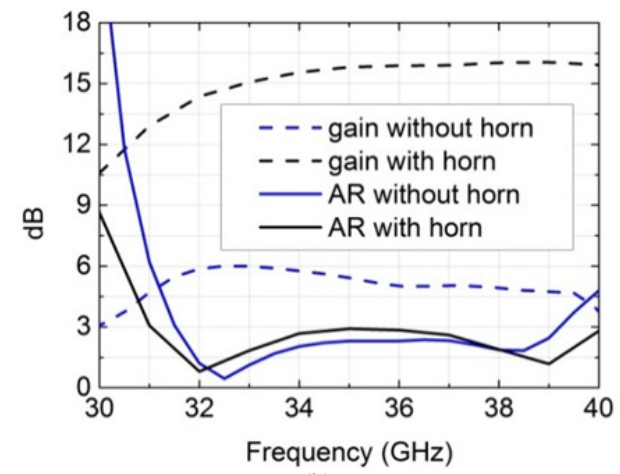

(b)

Fig. 12. Simulated (a) $\left|\mathrm{S}_{11}\right| \mathrm{s}$, (b) ARs and gains of the SIW antenna with and without the circular horn. 


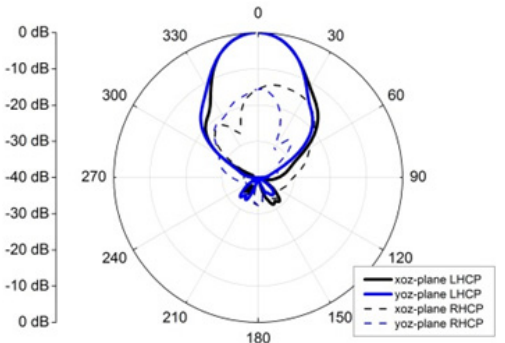

Fig. 13. Simulated radiation patterns of the SIW antenna with the circular horn at $35 \mathrm{GHz}$.

For illustrating the effect of the circular horn on the SIW antenna, the simulated $\left|\mathrm{S}_{11}\right| \mathrm{s}$, ARs and gains of the SIW antennas with and without the circular horn are shown in Fig. 12. As observed, the $\left|S_{11}\right|$ is improved by the loaded circular horn. The impedance bandwidth becomes $28.6 \%$ for $\left|\mathrm{S}_{11}\right| \leq-10 \mathrm{~dB}$ from 30 to $40 \mathrm{GHz}$. The maximum gain is increased greatly from 6 to $16 \mathrm{dBi}$. And the AR bandwidths of the SIW antennas with and without the circular horn are almost the same.

The simulated radiation patterns of the SIW antenna with the circular horn at $35 \mathrm{GHz}$ are shown in Fig. 13. It can be seen that good broadside radiation is also achieved. The FBR is increased to $47.8 \mathrm{dBi}$.

\section{Measured Results and Discussions}

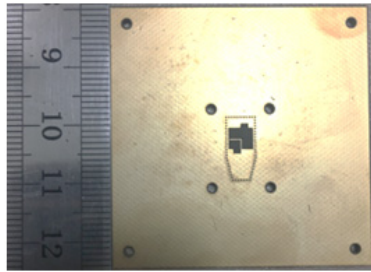

(a)

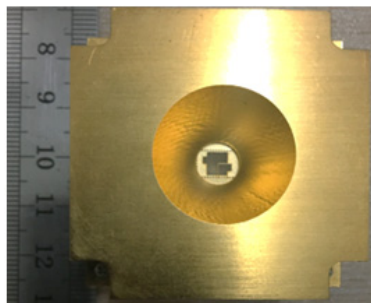

(c)

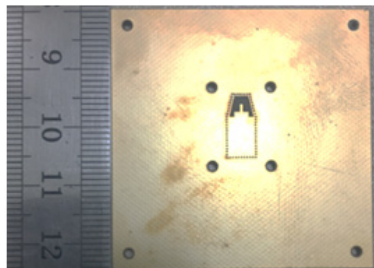

(b)

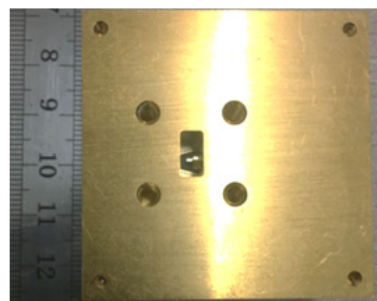

(d)

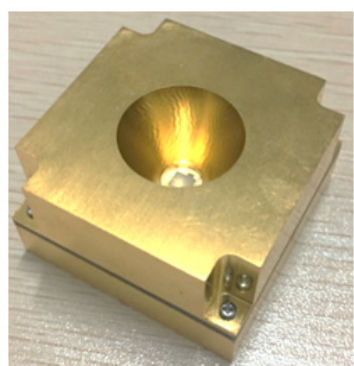

(e)

Fig. 14. Photographs of the antenna prototype: (a) Top and (b) back views of the SIW antenna, and (c) top, (b) back and (e) 3D views of the total antenna.

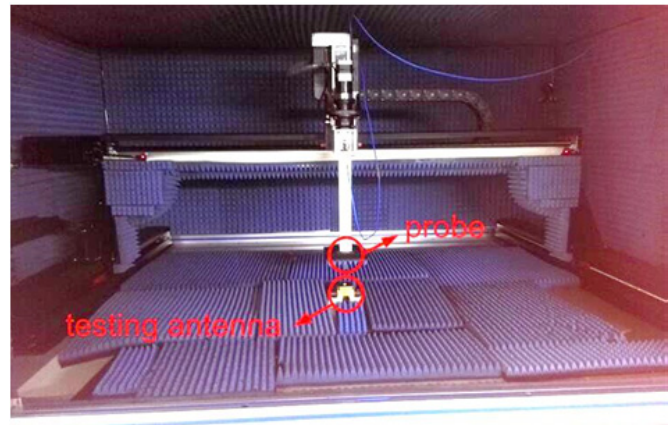

Fig. 15. Photo of the measurement setup.

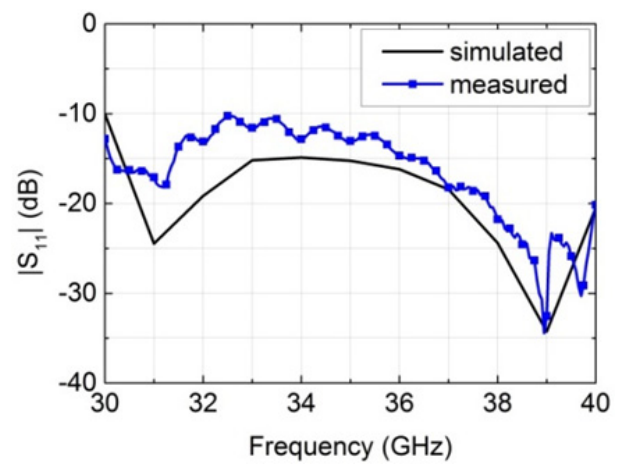

(a)

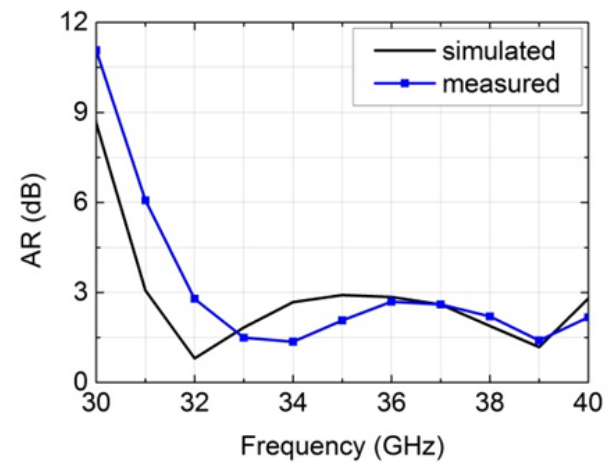

(b)

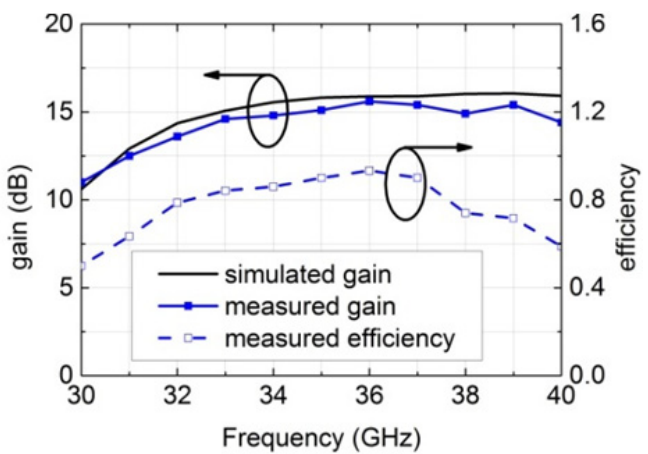

(c)

Fig. 16. Simulated and measured $\left|S_{11}\right| S$ (a), ARs (b) and gains (c).

To verify the simulations above, an antenna prototype was built and measured. Photographs of the antenna prototype are given in Fig. 14. The measurement setup is shown in Fig. 15. The measurement system is a near-field one. The distance between the antenna prototype and the probe is $35 \mathrm{~mm}$ and the detection range is $120 \mathrm{~mm} \times 120 \mathrm{~mm}$ 
with the detection step of $2 \mathrm{~mm}$. It should be noted that only the $\left|\mathrm{S}_{11}\right|$, AR, gain below $40 \mathrm{GHz}$ and the radiation patterns in the upper-half plane are measured due to the limitation of the experimental equipment.

The simulated and measured $\left|\mathrm{S}_{11}\right| \mathrm{s}$ ARs and gains are given in Fig. 16. It can be seen that the measured results agree well with the simulated ones. The antenna prototype has a wide impedance bandwidth of $28.6 \%$ from 30 to $40 \mathrm{GHz}$ for $\left|\mathrm{S}_{11}\right| \leq-10 \mathrm{~dB}$ and a wide axial 3-dB AR bandwidth of $22.2 \%$ from 32 to $40 \mathrm{GHz}$. The measured maximum gain is $15.6 \mathrm{dBi}$ at $36 \mathrm{GHz}$ with slight fluctuations over the $30-40-\mathrm{GHz}$ frequency range. The efficiency is about $80 \%$ within the working band and the maximum efficiency is $93 \%$ at $36 \mathrm{GHz}$.

Simulated and measured radiation patterns of the proposed array at 32, 35, and $39 \mathrm{GHz}$ are indicated in Fig. 17. It can be seen that good agreements are achieved between the simulated and measured radiation patterns. The LHCP components in both planes are generated as the co-polarization while the RHCP components in both planes are generated as the cross-polarization.

The slight discrepancy between measurements and simulations may be due to fabrication and assembling errors, and uncertainties, such as changes in the dielectric constant and thickness of the used substrate, metallization losses, and surface roughness.

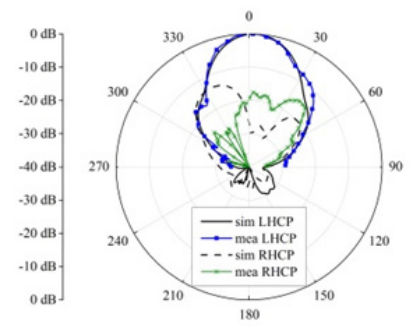

xoz-plane at $32 \mathrm{GHz}$

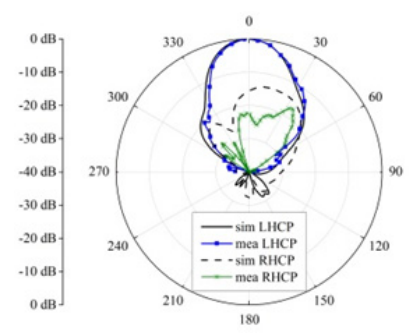

xoz-plane at $35 \mathrm{GHz}$

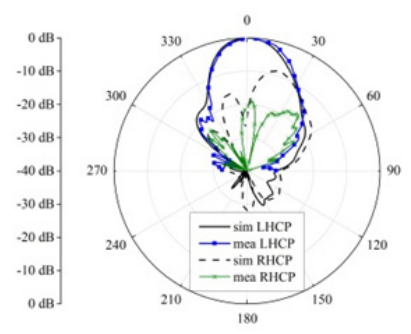

xoz-plane at $39 \mathrm{GHz}$

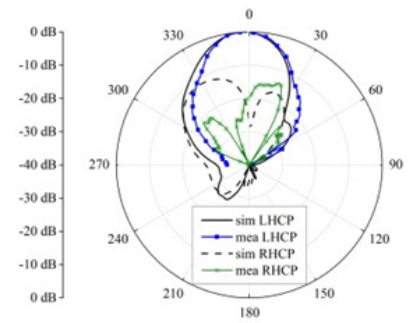

yoz-plane at $32 \mathrm{GHz}$

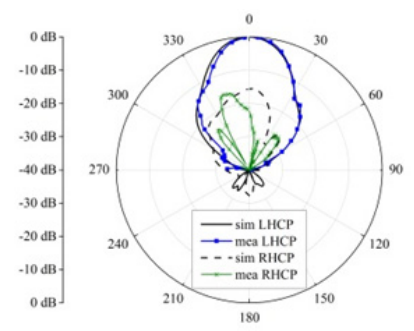

yoz-plane at $35 \mathrm{GHz}$

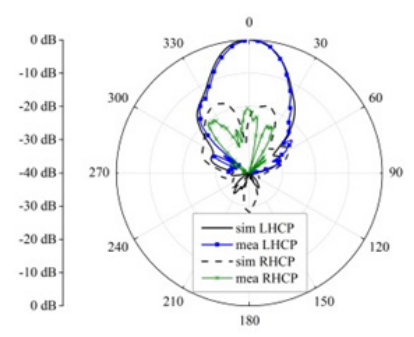

yoz-plane at $39 \mathrm{GHz}$
Fig. 17. Simulated and measured radiation patterns.

\section{Conclusion}

A low-cost circular-horn-loaded CP antenna based on SIW technology operating at $\mathrm{Ka}$ band is presented and demonstrated. The measured results show reasonable agreement with the simulated ones. This kind of $\mathrm{CP}$ antenna, which is single-fed, low-cost and high gain, has both wide impedance and 3-dB AR bandwidth. Owing to its advantages, this $\mathrm{CP}$ antenna can be a good candidate for the $\mathrm{mmW}$ applications.

\section{Acknowledgments}

This work was supported by the National Natural Science Foundation of China (No. 61401065), and China Scholarship Council (CSC).

\section{References}

[1] GUPTA, K. C., GARG, R., BAHL, I., BHARTIA, P. Microstrip Lines and Slotlines. $3^{\text {nd }}$ ed., rev. London (UK): Artech House, 1996. ISBN: 9780890067666

[2] BOZZI, M, GEORGIADIS, A, WU, K. Review of substrateintegrated waveguide circuits and antennas. IET Microwaves, Antennas and Propagation, 2011, vol. 5, no. 8, p. 909-920. DOI: 10.1049/IET-MAP.2010.0463

[3] LI, Z., WU, K. 24GHz FMCW radar front-end system on substrate. In 2007 IEEE Radio and Wireless Symposium. Long Beach (CA, USA), 2007, p. 233-236. DOI: 10.1109/RWS.2007.351810

[4] LI, Z, WU, K. 24-GHz frequency-modulation continuous-wave radar front-end system-on-substrate. IEEE Transactions on Microwave Theory and Techniques, 2008, vol. 56, no. 2, p. 278-285. DOI: 10.1109/TMTT.2007.914363

[5] WONG, S. W., WANG, K., CHEN, Z. N., CHU, Q. X. Design of millimeter-wave bandpass filter using electric coupling of substrate integrated waveguide (SIW). IEEE Microwave and Wireless Components Letters, 2014, vol. 24, no. 1, p. 26-28. DOI: 10.1109/LMWC.2013.2288177

[6] DING, Y., WU, K. A $4 \times 4$ ridge substrate integrated waveguide (RSIW) slot array antenna. IEEE Antennas and Wireless Propagation Letters, 2009, vol. 8, p. 561-564. DOI: 10.1109/LAWP.2009.2021006

[7] MALLAHZADEH, A. R., ESFANDIARPOUR, S. Wideband Hplane horn antenna based on ridge substrate integrated waveguide (RSIW). IEEE Antennas and Wireless Propagation Letters, 2012, vol. 11, p. 85-88. DOI: 10.1109/LAWP.2012.2183110

[8] JOHNSON, D.R., VOLAKIS. L. Antenna Engineering Handbook. $4^{\text {nd }}$ ed., rev. New York (USA): McGraw-Hill, 2007. ISBN-13: 9780071475747

[9] LI, Y., CHEN, Z.N., QING, X., et al. Axial ratio bandwidth enhancement of $60-\mathrm{GHz}$ substrate integrated waveguide-fed circularly polarized LTCC antenna array. IEEE Transactions on Antennas and Propagation, 2012, vol. 60, no. 10, p. 4619-4626. DOI: 10.1109 /TAP.2012.2207343

[10] LI, T., WANG, B., DOU, W. Substrate integrated waveguide slot array antenna covered by circularly polarised array patches. Electronics Letters, 2015, vol. 51, no. 21, p. 1634-1635. DOI: 10.1049/EL.2015.2206

[11] BISHARAT, D. J., LIAO, S., XUE, Q. High gain and low cost differentially fed circularly polarized planar aperture antenna for 
broadband millimeter-wave applications. IEEE Transactions on Antennas and Propagation, 2016, vol. 64, no. 1, p. 33-42. DOI: 10.1109/TAP.2015.2499750

[12] KIM, D., LEE, J. W., CHO, C. S., LEE, T. K. X-band circular ring-slot antenna embedded in single-layered SIW for circular polarisation. Electronics Letters, 2009, vol. 45, no. 13, p. 668-669. DOI: 10.1049/EL.2009.0901

[13] KIM, D. Y., LEE, J. W., LEE, T. K., CHO, C. S. Design of SIW cavity-backed circular-polarized antennas using two different feeding transitions. IEEE Transactions on Antennas and Propagation, 2011, vol. 59, no. 4, p. 1398-1403. DOI: 10.1109/TAP.2011.2109675

[14] DONG, J., YANG, Z., PENG, H., YANG, T. Full Ka-band rightangle transition from substrate integrated waveguide to air-filled rectangular waveguide. Electronics Letters, 2015 vol. 51, no. 22, p. 1796-1798. DOI: 10.1049/EL.2015.2462

[15] CHEN M, TSANDOULAS G. A wide-band square-waveguide array polarizer. IEEE Transactions on Antennas and Propagation, 1973, vol. 21, no. 3, p. 389-391. DOI: 10.1109/TAP.1973.1140486

[16] HUANG, Y., GENG, J., JIN, R., et al. A novel compact circularly polarized horn antenna. In 2014 IEEE Antennas and Propagation Society International Symposium (APSURSI). Memphis (TN, USA), 2014, p. 43-44. DOI: 10.1109/APS.2014.6904353

[17] MA, X., HUANG, C., PAN, W., et al. A dual circularly polarized horn antenna in Ku-band based on chiral metamaterial. IEEE Transactions on Antennas and Propagation, 2014, vol. 62, no. 4, p. 2307-2311. DOI: 10.1109/TAP.2014.2301841

[18] GAN, T. H., TAN, E. L. Design of waveguide fed broadband circular polarization truncated horn antenna for high power applications. In 2011 Asia-Pacific. IEEE Microwave Conference Proceedings (APMC). Melbourne (Australia), 2011, p. 1194-1197.

[19] FUKUSAKO, T, SHAFAI, L. Design of broadband circularly polarized horn antenna using an L-shaped probe. In IEEE Antennas and Propagation Society International Symposium. Albuquerque (USA), 2006, p. 3161-3164. DOI: 10.1109/APS.2006.1711281

\section{About the Authors ...}

Ming DU was born in China in 1989. He received the B.S. degree in Electrical Engineering from the University of
Electronic Science and Technology of China (UESTC) Chengdu, China, in 2011, and is currently pursuing the Ph.D. degree in UESTC. His research interests include microwave wave circuits and antennas.

Jun XU was born in China in 1963. He received the B.S. degree in 1984, and M.S. degree in 1990 from the University of Electronic Science and Technology of China (UESTC) Chengdu, China. He engaged in basic research in the field of radio physics subject and teaching work. He was hired as an associate professor in 1997, then as a professor in 2000 in UESTC. His main research interests include microwave theory and technology, millimeter-wave hybrid integrated technology, millimeter-wave communication and radar radio frequency technology. He has published over 80 papers in refereed journals.

Yuliang DONG was born in Sichuan, China, in 1972. He received the B.S. degree in Electronic Engineering from the Northwestern Polytechnical University, Xi'an, China, in 1993, and Ph.D. degree from Beihang University, Beijing, in 2005. He is now working in the Institute of Applied Physics, University of Electronic Science and Technology of China, No.4, Section 2, North Jianshe Road, Chengdu, Sichuan, 610054, China. His research interests include microwave wave circuits, passive components, antennas and microwave CAD technology.

Xiao DING was born in Sichuan, China, in 1982. He received the Ph.D. degree in Radio Physics from the University of Electronic Science and Technology of China (UESTC), Chengdu, China, in 2013. He joined UESTC in 2014, where he is currently an associate professor. He has been a Visiting Scholar at the South Dakota School of Mines and Technology, SD, USA, a Visiting Fellow with the University of Houston, TX, USA. His research interests include wide-angle scanning phased array, LTCC millimeter wave array and reconfigurable antenna and its applications. 